bamic acid is present in the urine of a normal animal, and increases after Fek's optration. It would be interesting thereforc to compare these facts with what we know of the increase of ammonia in pathological states of the liver in man. The liver, however, is not the only place where urea is formed, for the urea never completely disappeared in any of these experiments; and it is well known that in sharks which live seventy hours after the removal of the liver, the urea in the muscles does not diminish after the operation.

Such are the chief new facts we have met with in this interesting memoir, and it is certain that these investigations open up a new field for further researches. The other papers ${ }^{1}$ contained in this volume call for little comment; they relate chietly to the digestive and putrcfactive processes taking place in the human intesinal tract.

It will be scen, however, that this fourth number sustain the well-earned reputation of the three first ones, and that the archives deserve to take their place among the chief scien tific journals which made their first appearance in the year 1892 .

\section{STEAM ENGINE TRIALS.}

$A$ PAPER on the last series of steam engine trials underlaken by the late Mr. P. W. Willans was read at the meeting of the Institution of Civil Enginecrs on $\Lambda$ pril 1 I.

The paper dealt with an extensive series of condensing trials made with a 40 l.ll,P. Willans Central-Valve Engine. These were intended to form a, sequel to the investigations described in the author's papers, entitled "Economy Trials of a Non-condensing Steam Engine, Simple, Compound, and Triple," read betore the Institution in 1888 and 1889 . The principal objects in undertaking these trials were-( 1 ) To ascertain the initial condensation in the frst cylinder, and to trace the behaviour of the steam in the succeeding cylinders, when working as a compound or triple-expansion engine; (2) To observe the effect of speed of rotation, area of exposed surface, and range of temperature, upon the initial condensation, and upon economy generally; (3) To ascertain the percentage of the theoretical mean pressure actually obtained; $(4)$ To asceriain the ratio of the work done by each pound of sieam to the theoretical work due from it; (5) To determine the consumption of steam at all loads, and under various condutions.

The consumption of stcam was determined by discharging the condensed water from the exhaust into a tank carried by a weigh. bridge, and observing the intervals of time requircd for fixed weights of watcr to run in. Ry this method, a continual watch was kept on the performance of the engine during the whole trial, and any disturbing cause was immediately detected; leaky steam-pipe joints did not affect the result, and the length of the trial might be much reduced. Special experiments, made to ascertain whether any addition was necessary to cover leakage in the engine and exhatut-pipe, showed that this leakage was slight.

The method of determining the theoretical work due fiom one pound of satirated steam when discharging into a condenser was next considered, and it was shown that the thermal efficiency of a condensing engine must of necessity be less than that of a nun-condensing engine, owing to the greater proportionate size of the "toe" of the diagram cut off for practical reasons. In the non-condensing trials the best number of expansions was compated from the approximate formula $p^{3} v^{\bar{z}}-$ constant ; but for the condensing trials the error in this could not be neglected. The best ratio of expansion and mean pressure were therefore calculated for adiabatic expansion, by Mr. Macfarlane Gray's $\theta$ p liagram, combined with a volume curve. Altogether sixty-two trials were made under various conditions of speed, steam-pressure, load, and ratio of expansion, as well as with the engine working simple, compound, and triple, and the results were embodied in the tables accompanying the paper.

One of the principal deductions from these experiments was the "straight-line" law of steam-consumption; and it was shown by diagrams that the lolal water for the horse-power

I "On the Pintrefactive Processes in the Large Intestine of Man and on the Microbes Causing Them," by M. Lumft. "On the Micro-organism in the Organs of Chulcraic Patients," by M. L. de Relowski. "Contri hutions to t le Study of Chemical Processes in the lntestines of Man," by M. Jakowski.

NO. 1225 , VOL. 47$]$ corresponding to any mean pressure $P$, was $W+K . P$., where W was the water which would be used by the engine at zero mean pressure (through initial condensation, radiation and conduction), supposing it were frictionless, and $\mathrm{K}$ was the water per hour required to produce each pound of mean pressure. These factors were shown to vary with the conditions under which the engine was working.

Eighteen of the trials wcrc planned to assist in detcrmining the law connecting initial condensation w ith revolutions; and it was found that in the high-pressure colinder at high mean pressures the total condensation per unit of time was directly proportional to the square root of the number of revolutions per unit of time. As the mean pressure was diminished, the conden-ation became more and more nearly constant at al speeds; and finally, at low mean pressures, the law appeared to be reversed. For the low-prensure cylinder, the law was modified.

The important question of the changing proportions of steam and water present during the expansive part of the strohe was investigated hy the $\theta \phi$ diagram. The matter was first examined theorelically by considering the effect of a thin liner of infinitely conducting malter, and a curve was drawn on the $\theta \phi$ diagram showing the rate at which the steam initially condensed in warming up the liner from the exhaust to the initial temperaature was re-evaporated as the expansion proceeded. The actual re-evaporation, as obtained by measurement of the indicator cards was compared with this theoretical re evapora. tion, the dillerence measuring the delay in the return of the heat from the liner to the sterus. The losses due to conduction and radiation, 10 passage through ports, and to incomplete expansion, could also be shown on the $\theta \phi$ diagrams.

The question of the economical advantage of reducing the power by automatic cut-oft virsus throttling was discussed. Broadly, the result was that the gain by varying the expansion was large for a simple cngine, modrate for a compound engine, and, for a triple engine, almost inappreciable. It further appeared that the gain at high speeds was greater than at low speeds.

A fow trials made with the cylinders steam jacketed showed a slight gain, but further experiments were required to show whether the gain was likely to be worth the extra trouble and expense involved.

The missing steam at cut-of varied in the trials to even a greater extent than it did in the non-condensing trials-the amount being much affected by the range of temperature, the density of the steam, and by other conditions.

It appeared that, under all circumstances, the triple-condens ing engine showed an advantage over the compound in regard to steam-consumption; but that, except for very large engines, the compound-transfer engine was probatly the best for pres. sures below i 50 lbs. (absolute) pressure per square inch.

\section{ETHNOLOGICAL OBSERVATIONS IN AUSTRALIA.}

SOME time ago Mr. R. Wtheridge, jun., carried on a series of geological and ethnological investigations in the valley of the Wollondilly River, at its junction with the Nattai River, New South Wales; and in the latest number of the "Records of the Australian Mruseum" (vol. ii. No. 4) he gives an interesting account of the various facts he had occasion to study The following is the greater part of the passage in which he records his ethnological observations :--

The aborigines of the Wollondilly and Nallai Valleys, musl, from local accounts, have existed in considerable numbers, and are now only represented by interments, carved trees, wizards' hands, and charcoal drawings in rock shelters alons the precipitous escarpments.

The first objects investigated under this head were the "IIands-on-the-Rock." The "rock" consists of a huge mass of Hawkesbury Sandstone, about seventeen feet in breadth and length, hollowed out on the side overlooking the river to the extent of six feet. It is perched on the side of a gentle rise from the Wollondilly, having rolled from the higher ground alsove, and alongside the track from the Nattai Junction to Cox's River, in the immediate south-west corner of the Parish Werriberri. The cavernous front of the rock is fifteen feet 